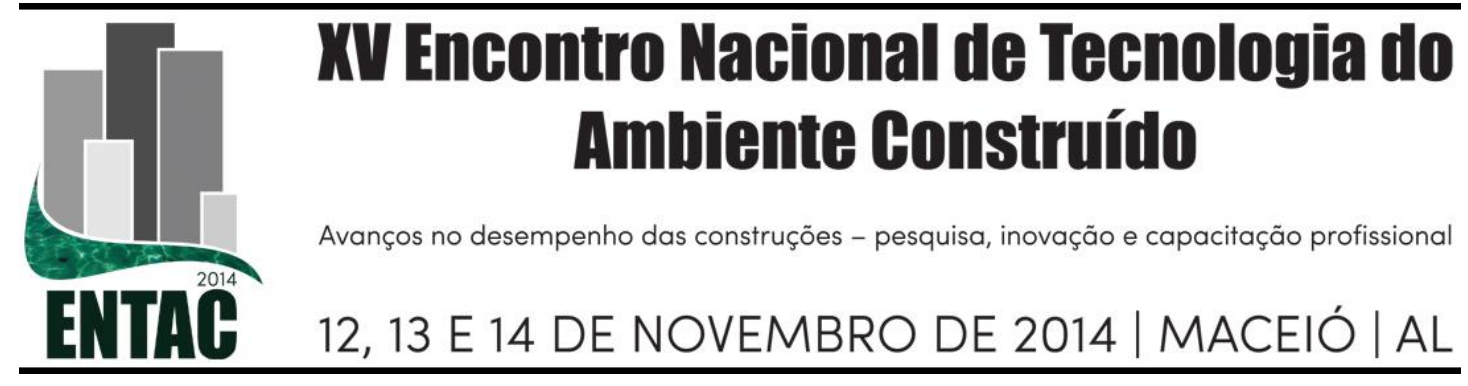

\title{
A GESTÃO DO PROJETO EM UMA EMPRESA CONSTRUTORA: ESTUDO DE CASO
}

\author{
CARRARO, Marília (1); MELHADO, Silvio B.
}

(1) IPT, e-mail: carraro.marilia@gmail.com (2) USP, e-mail: silvio.melhado@poli.usp.br.

\begin{abstract}
RESUMO
A relação entre as etapas do empreendimento, desde sua concepção à execução da obra tem importância reconhecida entre os pesquisadores e também reflete nas decisões de gestão de muitas empresas. A fase de projeto ganha destaque por representar um elo entre a idealização do empreendimento e a obra; e o momento de maior potencial de intervenção no processo sem comprometimento da qualidade do produto. Este trabalho objetiva discutir aspectos de gestão e coordenação de projeto através do estudo de caso de uma empresa incorporadora e construtora de médio porte em São Paulo; confrontando os dados com conceitos discutidos na bibliografia. $O$ porte e a atuação da Empresa estudada permitem o desenvolvimento potencial de um processo coeso. Busca-se discutir suas práticas com atenção a princípios de projeto simultâneo e qualidade do processo. E a partir desta análise propor melhorias.
\end{abstract}

Palavras-chave: Processo de projeto; Coordenação de projeto, Retroalimentação, Inovação.

\begin{abstract}
The relation between the project phases, from conception to construction, is important according to researchers and also reflects management decisions of many companies. The design management represents a strong link between product development and its construction. It is also the moment to make changes which results tend to be committed to the quality of the whole project. This paper aims to discuss design management concepts based in the literature and the practices of a company engaged in real estate development and construction in São Paulo. The activities under its control allow the potential development of a cohesive process. This analysis attempts to propose improvements to the company process, considering discussions about design management, concurrent design and process quality.
\end{abstract}

Keywords: Design management; Feedback, Innovation

\section{INTRODUÇÃO}

De acordo com Fontenelle (2002), há duas interfaces principais no processo de projeto. A primeira, entre a etapa de concepção do produto e o projeto, é marcada pela presença das definições do incorporador e mercadológicas. A segunda, entre o projeto e a produção, consiste nas soluções tecnológicas, no atendimento às normas e na adequação às técnicas dominadas pelo construtor.

A empresa estudada encontra dificuldades na implantação de procedimentos para uma gestão coesa da construção, como ocorre em outras organizações do mesmo porte. No entanto, a concentração das atividades de incorporação, coordenação de projeto e construção tende a facilitar a interação entre as áreas e etapas. 
O trabalho objetiva discutir aspectos de gestão e coordenação de projeto através do estudo de caso de uma construtora de médio porte em São Paulo. Visando a interação entre as fases da construção, foi feita uma análise das práticas de gestão e sua eficácia, confrontando-a com a bibliografia consultada.

\section{PROJETO NA CONSTRUÇÃO DE EDIFÍCIOS}

\subsection{Gestão do projeto}

Melhado e Agopyan (BT193:1995) definem projeto como: "atividade ou serviço integrante do processo de construção, responsável pelo desenvolvimento, organização, registro e transmissão das características físicas e tecnológicas especificadas para uma obra, a serem consideradas na fase de execução."

Tzortzopoulos (1999) defende que a partir de uma visão ampliada do processo de projeto não é possível dissocia-lo da gestão do empreendimento e quando esta interação faz parte do processo, a condução torna-se mais simples e viabiliza a melhoria contínua nas soluções desta interface. Cabe, portanto, à gestão do projeto garantir um processo interativo e integrado.

O processo de projeto convencional é de natureza interativa e nele é preciso converter a expectativa abstrata do empreendedor em proposta arquitetônica. (CHUA, ASCE, et al., 2003).

É também uma visão recorrente entre os autores consultados, a necessidade de buscar-se um processo multidisciplinar, com participação dos agentes nas diversas etapas, e uma gestão focada em atender ao objetivo do empreendimento (produto concebido) e dos usuários finais (edificação construída).

De acordo com Tzortzopoulos (1999), para atingir estes objetivos é necessária a redução de incertezas nas fases iniciais do processo, através da definição ordenada do escopo do projeto e da consideração de todo o ciclo de vida útil da edificação.

\subsection{Integração entre agentes e etapas}

O processo de projeto na construção civil envolve cada vez mais especialidades e tornase mais complexo à medida que exigências de prazo, custo e desempenho são maiores.

$\mathrm{Na}$ etapa de projeto devem ser equacionadas as principais questões; atrelando as decisões tomadas pela incorporação na elaboração do produto às questões construtivas. O projeto é muitas vezes deixado em segundo plano, focando-se em metas de prazo e custo. É necessário investir nesta fase para ter melhor controle da qualidade da construção. De acordo com Oliveira (2005) é preciso que a etapa de projeto receba atenção e seu prazo permita incorporar todas as questões inerentes à execução, minimizando improvisações em obra.

A elaboração do projeto em um processo coeso e multidisciplinar tende a reduzir conflitos e erros na obra e, portanto, seu prazo e custo. Assim, também, podem ser reduzidas patologias, que geram a insatisfação do cliente final e elevam os custos manutenção do edifício.

Como alternativa ao processo fragmentado que marca o cenário da construção, autores buscam práticas consolidadas em outras indústrias. A engenharia simultânea ganhou uma leitura própria para a construção, buscando soluções mais integradas.

Fabricio (2002) trata o projeto simultâneo na construção civil como: " $O$ desenvolvimento integrado das diferentes dimensões do empreendimento, envolvendo a formulação conjunta da operação imobiliária, do programa de necessidades, da 
concepção arquitetônica e tecnológica do edifício e do projeto para produção, realizado por meio da colaboração entre o agente promotor, a construtora e os projetistas, considerando as funções subempreiteiros e fornecedores de materiais, de forma a orientar o projeto à qualidade ao longo do ciclo de produção e uso do empreendimento".

O autor citado aponta como elementos do Projeto simultâneo: integração dos diversos agentes desde as primeiras etapas de projeto, valorização da cooperação técnica entre as disciplinas, coordenação simultânea dos interesses do projeto e utilização de tecnologia para garantir a interface frequente. De modo que se possa atingir: maior qualidade do projeto e da construção, amparar a introdução de novas tecnologias e buscar projetos de mais rápida execução (FABRICIO, 2002).

Oliveira (2005) ainda defende que quanto mais cedo são tomadas as decisões, maior seu potencial de influenciar o custo e o desempenho do edifício. Portanto, as soluções devem ser pensadas dentro do contexto global do empreendimento, considerando os requisitos de todas as suas fases.

Este processo poderia ser mais natural em uma organização que concentra estas etapas e interesses. Sendo necessário, ainda assim, procedimentos para integração e equalização das disciplinas. Visto que se trata de um processo sistêmico, se os agentes não podem garantir a consonância das soluções, deve haver um profissional responsável por esta coordenação de interesses.

\subsection{Coordenação de projetos}

O coordenador de projetos assume papel fundamental na transição entre as etapas. Segundo Nóbrega Junior e Melhado (2013), ele é responsável por garantir a compatibilidade entre as soluções de projeto e destas com o produto concebido pelo empreendedor; buscar o feedback da obra e alinhar o projeto com a estas solicitações. Deve, ainda, estar atualizado quanto às novas soluções construtivas e direcionar o projeto ao cumprimento das normas aplicáveis.

Dentre as principais habilidades do coordenador de projetos estão: uma visão sistêmica do processo, a capacidade de planejar e de gerenciar a equipe; representando de forma imparcial os interesses do projeto (empreendedor) e atuando na interface entre os agentes especialistas do processo. (NÓBREGA JUNIOR e MELHADO, 2013).

Um número crescente de agentes envolvidos no processo da construção prescinde do papel do coordenador para eficiência do empreendimento como um todo (FONTENELLE, 2002). Silva e Novaes (2008) definem os coordenadores de projeto como profissionais com uma visão completa do processo; cujo conhecimento técnico permite analisar as soluções das diversas especialidades, controlar o fluxo de informações e integrar os agentes envolvidos. E Laufer, Denker e Shenhar, (1996) destacam sua função de facilitador do processo, garantindo o fluxo de informações e o elo entre cliente, projetistas e construtor.

O papel deste agente integrador é de suma importância para o andamento do processo sistêmico e multidisciplinar, discutido anteriormente. Sua atuação viabiliza a integração entre as etapas, a compatibilização de soluções técnicas, a fidelidade às características fundamentais pré-estabelecidas e a qualidade do projeto em termos de construtibilidade, desempenho técnico e ambiental e resultados de prazo e de custo.

Laufer, Denker e Shenhar (1996) destacam, ainda, o papel do coordenador em estimular o processo criativo e a inovação, especialmente nas fases iniciais do projeto. 


\subsection{Qualidade do projeto}

Laufer, Denker e Shenhar (1996) apontam os principais quesitos a serem atendidos no processo para a qualidade do projeto: planejamento sistemático, integração de requisitos internos e externos; integração entre as etapas, equipes multidisciplinares, formalização de procedimentos, aplicação de mecanismos de controle e comunicação constante.

Os autores acima ainda esclarecem a necessidade de cada agente ter consciência de sua responsabilidade técnica especializada e, também, de seu papel no conjunto. O processo requer a análise global e a validação de um coordenador, mas não deve ser atribuída a ele a análise de questões técnicas intrínsecas aos projetos específicos; permitindo que este dedique seu tempo às interfaces mais relevantes.

\section{ESTUDO DE CASO}

O estudo de caso foi realizado no período de outubro e novembro de 2013. A pesquisa baseou-se em entrevista semiestruturada com os responsáveis pela coordenação de projetos. Bem como, na análise de relatórios, atas, cronogramas e projetos disponibilizados pela Empresa.

\subsection{Caracterização da empresa}

A Empresa, situada em São Paulo, foi fundada em 1979 e está no mercado com sua configuração atual há 17 anos, após uma divisão coorporativa. Possui cerca de 300 funcionários e atua com incorporação, construção, detalhamento e gerenciamento de projetos. É certificada pelo PBQP, nível A, e ISO 9001.

Sua atuação é direcionada para um recorte de mercado específico: edifícios residenciais multipavimentos, com apartamentos de área entre 50 e $120 \mathrm{~m}^{2}$, frequentemente situados no bairro do Morumbi.

A Empresa depara-se com um desafio recorrente no setor: aliar a expansão ao controle e manutenção da qualidade dos serviços prestados.

A fim de definir melhorias na produtividade e perpetuar o conhecimento gerado pela sua experiência, a Empresa passa por uma reestruturação. Deste modo, algumas funções foram redefinidas, conforme organograma da Figura 1.

Figura 1 - Organograma da Empresa (foco no departamento de projeto)

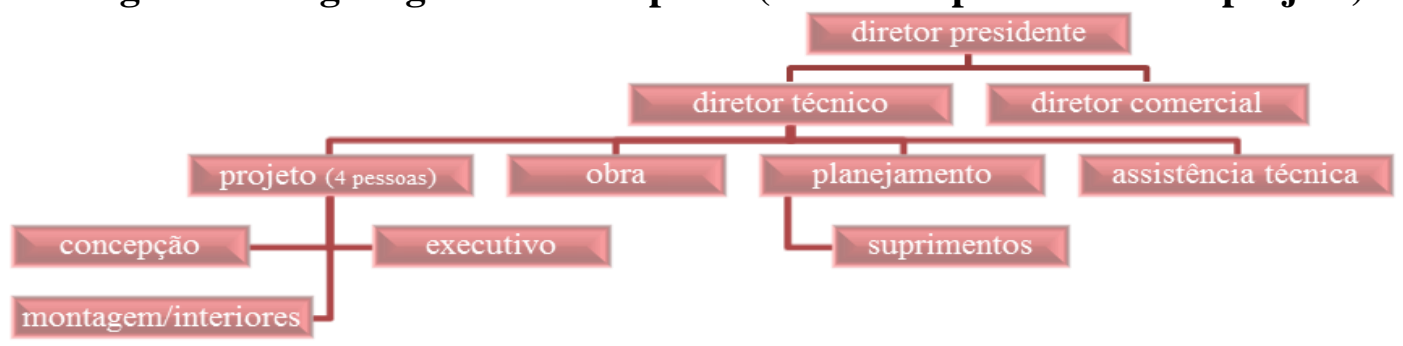

Fonte: Elaborado pela autora, baseado em dados da entrevista com a gerente de projeto.

\subsection{Principais envolvidos com o processo de projeto}

Como parte da mudança já mencionada, houve uma redefinição de responsabilidades no departamento de projetos. Destacando-se os agentes abaixo, como os principais protagonistas do processo:

Diretor presidente: Inicia, acompanha e valida as principais decisões relacionadas à incorporação e concepção do produto. 
Diretor técnico: Participa do projeto desde a concepção inicial e está em contato diário com as equipes de projeto e obra. É o principal agente da retroalimentação na empresa.

Gerente de projetos: Arquiteta responsável pelo desenvolvimento do produto, elaboração das diretrizes de projeto e coordenação dos projetistas na etapa inicial. Coordena, também, a confecção do material de vendas e a aprovação legal.

Coordenadora de projeto (executivo): Arquiteta responsável pela coordenação dos projetos a partir da aprovação do Legal. Compatibiliza e valida os projetos para mudança de fase e responde pela elaboração interna do detalhamento construtivo.

Vale destacar que a atuação conjunta dos três últimos profissionais configura o que seria a função de um coordenador de projetos, conforme definido pela bibliografia discutida anteriormente. Os agentes participam das etapas como indicado no Quadro 1.

Quadro 1 - Relação entre os agentes e as etapas do empreendimento

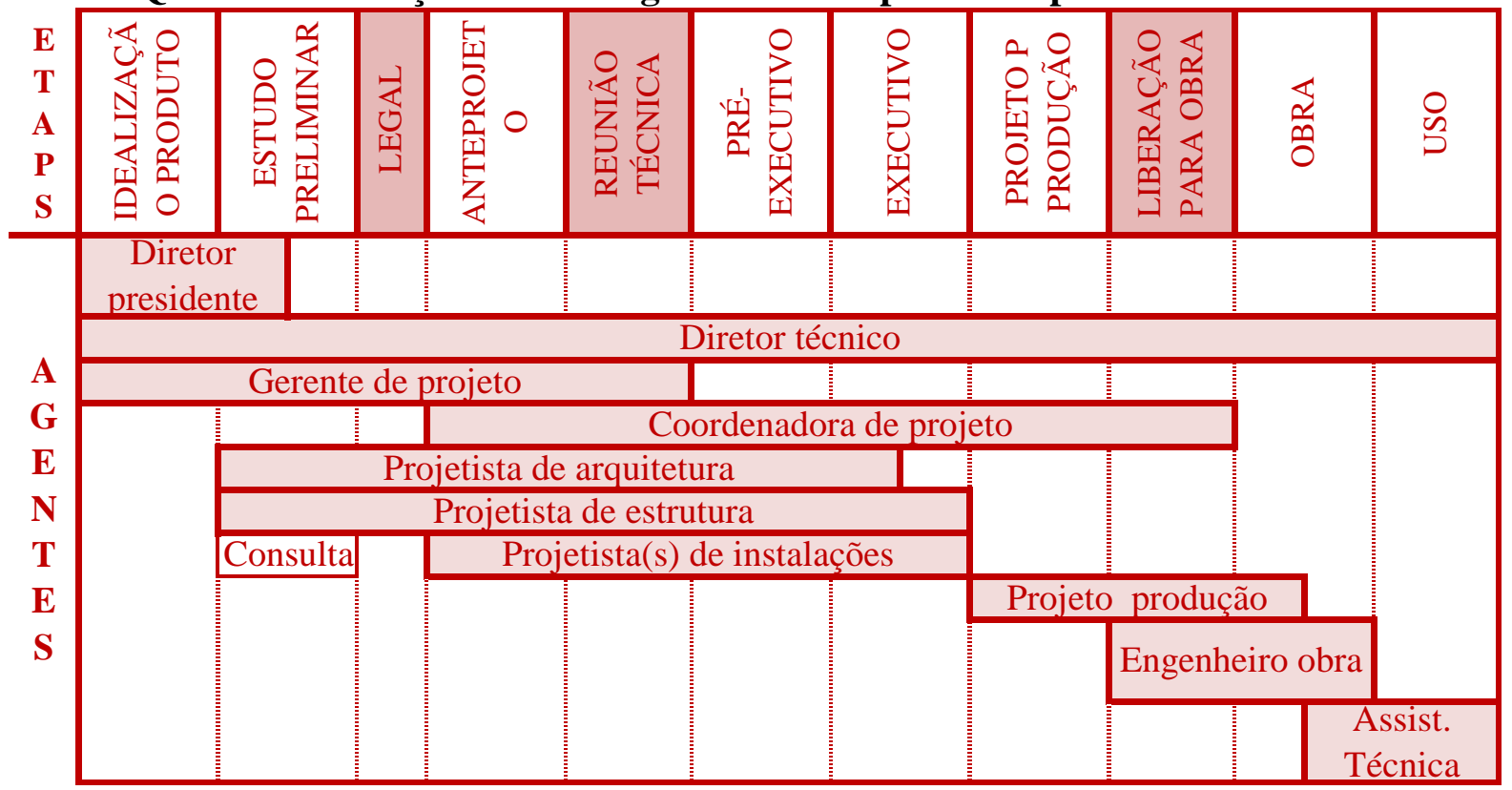

Fonte: elaborado pela autora

\subsection{Relação com os projetistas}

Os projetistas são contratados pelo Diretor Técnico dentro de um grupo bastante restrito com que a construtora vem trabalhando nos últimos anos. Os escritórios responsáveis pela arquitetura e estrutura são parcerias fixas. Não há interesse por parte da Empresa em avaliar e selecionar novos colaboradores devido ao domínio que estes têm das soluções praticadas e a qualidade técnica e confiabilidade do projeto fornecido.

A arquitetura terceirizada é contratada apenas até a fase do pré-executivo. A compatibilização e o detalhamento são desenvolvidos internamente, a fim de facilitar a adequação à cultura construtiva da Empresa. Recentemente tem havido casos em que a Empresa não pode absorver estas atividades, buscando estabelecer parcerias para tal.

No caso dos projetos de instalações, há alguns escritórios que atuam como parceiros. Quando existem problemas na qualidade do serviço, estes são discutidos com a diretoria. A avaliação dos projetistas é feita durante o processo de modo informal, não havendo critérios padronizados, tão pouco, um catálogo de projetistas habilitados.

As diretrizes são fornecidas pela Gerente no início do desenvolvimento do projeto. Complementarmente, esta padronização é afinada em diversas trocas de e-mails, telefonemas e relatórios. 
O "Manual de projeto" e o "Caderno de Detalhes" da Empresa estão em processo de estruturação e atualmente não são utilizados como Input para novos membros da equipe ou projetistas. Juntando-se a isso o fato do contrato não contemplar uma descrição detalhada do escopo, quando da necessidade de formar novos parceiros, encontra-se dificuldade, gerando retrabalho para eles e grande esforço da coordenadora na compatibilização.

Notadamente, as parcerias consolidadas, combinadas à semelhança entre os produtos oferecidos, facilitam a aplicação dos padrões e da cultura construtiva da Empresa. Contudo, também representam entraves para a inovação.

\subsection{Etapas de projeto na empresa}

A Figura 2 sintetiza as principais atividades do projeto até a liberação para obra. As etapas de execução e uso não são apresentadas na ilustração, uma vez que estão fora do domínio do departamento de projeto. Sendo o vínculo entre estas fases diretamente dependente da atuação do diretor técnico, como se pôde ver na Figura 1.

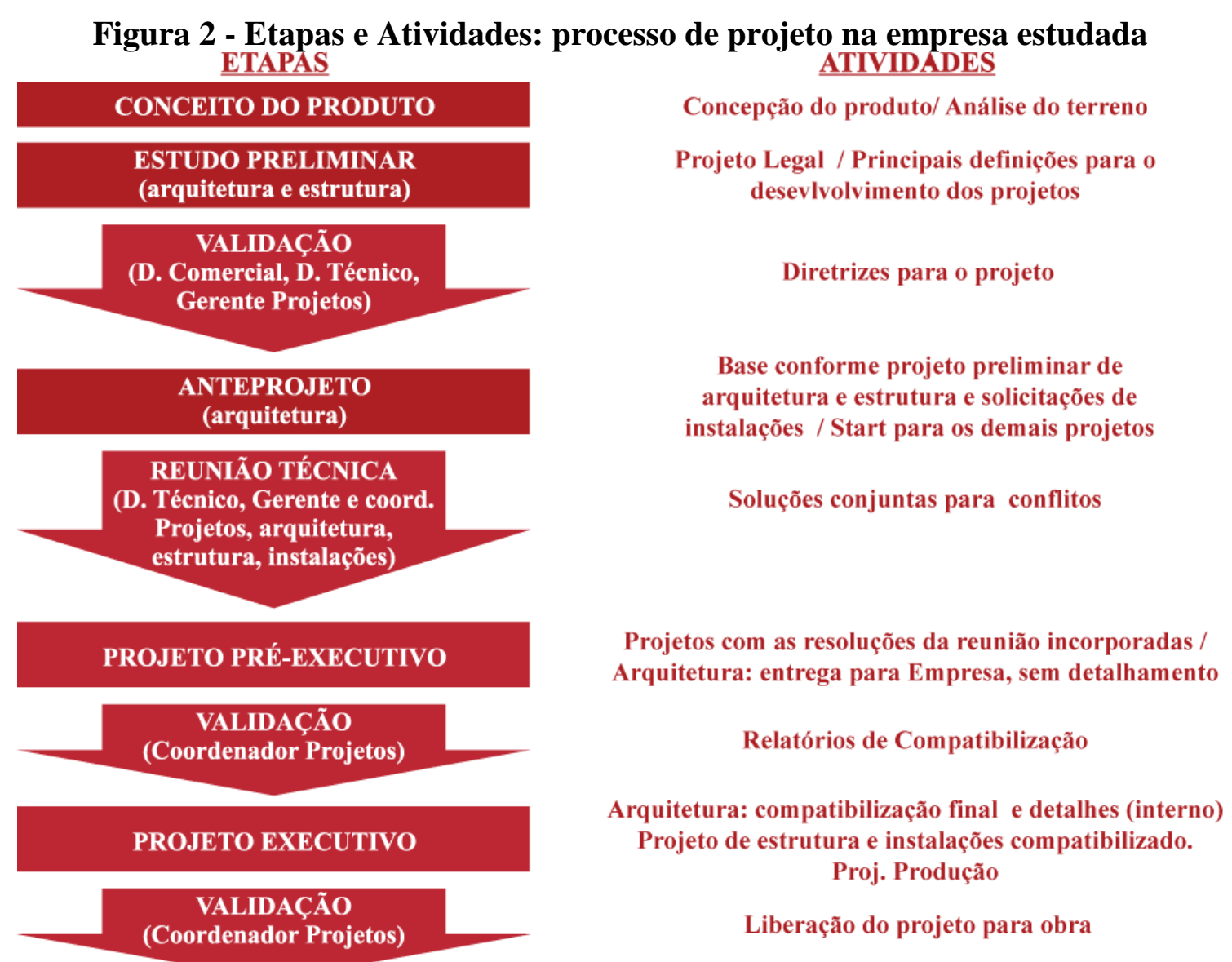

Fonte: elaborado pela autora

Segue a descrição das etapas de projeto praticadas na empresa:

\subsubsection{Estudo preliminar:}

Esta etapa engloba a idealização do produto, com frequentes trocas e revisões entre os estudos iniciais de projeto e a definição do empreendimento.

O programa elaborado pela diretoria gera a solicitação de um estudo; cuja forma é definida conjuntamente pelos diretores técnico e comercial, gerente de projeto e arquiteto terceirizado. São estudadas propostas, primeiramente para o pavimento tipo, 
de maior impacto e, posteriormente, para os demais. Cada versão é discutida até passar pelo crivo de todos os envolvidos. Ainda nesta etapa, os projetistas fazem um prédimensionamento da estrutura e um relatório de instalações. Embora antes da contratação, a consultoria é fornecida em nome das parcerias já realizadas.

O produto desta etapa é o Projeto Legal, contemplando: pré-compatibilização, precisão dimensional e definição de soluções técnicas e especificações. Não se costuma retroceder as decisões desta fase, validada pelos diretores presidente e técnico (sob consulta ao departamento de projetos). A partir disto, é estabelecido o prazo de início da obra, que passa a ser uma importante meta no processo.

A colaboração de todas as disciplinas na elaboração do projeto legal; bem como a análise crítica dos diretores antes da sua liberação, constituem ferramentas de suma importância para evitar grandes retrabalhos em etapas posteriores. De acordo com Kpamma e Adjei-Kumi (2011), a redução de incertezas na fase inicial é um dos principais meios de evitar o desperdício na fase de projeto.

\subsubsection{Anteprojeto:}

Com todos os projetistas já contratados, a Gerente libera as diretrizes de projeto e a emissão inicial do Anteprojeto de arquitetura (com o estudo preliminar da estrutura e os comentários de instalações incorporados) para que os demais projetistas iniciem seu trabalho.

Após a primeira emissão do jogo completo de projetos (arquitetura, estrutura e instalações), é realizada a Reunião Técnica, organizada pela Coordenadora de Projetos, com a presença de todos os projetistas envolvidos. Normalmente esta é a única reunião presencial com todas as disciplinas e marca claramente a transição entre fases. Participam, também, a gerente de projetos e o diretor técnico, que tem contato diário com as obras e trás contribuiçõos da mesma para esta etapa de definições.

Esta reunião é quando a multidisciplinaridade do projeto é evidenciada, discutindo-se as interfaces entre as disciplinas com o respaldo da Coordenadora. Esta é responsável, também, pelo controle do posterior emprego das soluções deliberadas em reunião. Segundo Laufer, Denker e Shenhar (1996), ainda que as ferramentas tecnológicas tenham importante papel no processo, reuniões presenciais são indispensáveis, pois permitem um feedback instantâneo e facilitam a elaboração de soluções para atender às necessidades de todos os presentes.

\subsubsection{Projeto executivo:}

A partir das definições da reunião técnica, os projetistas emitem o projeto executivo para compatibilização final pela Coordenadora de projetos. No caso da arquitetura, o escritório emite um Pré-executivo que será complementado internamente.

A análise dos projetos gera relatórios e através deles é demandado o enquadramento nas soluções gerais do empreendimento. Este processo é cíclico até que as disciplinas contemplem todos os requisitos, possibilitando a liberação dos projetos para obra responsabilidade da Coordenadora.

\subsubsection{Projetos para produção}

A empresa usa apenas alguns projetos para a produção: Alvenaria, Marcação de pilares, posicionamento de instalações na laje e, às vezes, projeto de fôrmas. Estes projetos são desenvolvidos por um parceiro antigo que mantém relação direta com a obra. Suas visitas frequentes às obras permitem que atualize e agregue informações aos projetos sem depender diretamente do Coordenador; embora esteja submetido a ele. 
Este vínculo direto entre o projetista e a obra dá substância ao projeto de produção; contudo, tira da coordenação o efetivo domínio sobre os aspectos construtivos, dificultando a incorporação de ajustes em projetos futuros e, até mesmo, a contratação de outro profissional para desempenhar este papel.

\subsubsection{Coordenação}

O controle dos produtos e dos agentes envolvidos é de responsabilidade da Gerente de projetos até o início do Anteprojeto. Já nesta fase, a Coordenadora de projetos dá sequência a estas atividades.

O controle de prazos, a coordenação de entregas e a gestão da informação são feitas por mecanismos não sistemáticos, sem indicadores pré-estabelecidos. Portanto, $\mathrm{o}$ funcionamento depende da experiência dos profissionais envolvidos no processo e da coesão da equipe.

As informações são passadas através dos relatórios de análise e validação dos projetos durante o processo; ou ainda, e-mails e telefonemas. Apenas a troca de arquivos de projeto é feita por um sistema unificado, que auxilia no controle de entregas e revisões. Estes meios têm funcionado, mas ainda podem ser aprimorados. Tribelsky e Sacks (2011) constataram, em sua pesquisa, uma qualidade superior do projeto, quando elaborado por equipes com um fluxo contínuo e controlado de informações.

A elaboração do projeto Legal e a Reunião técnica marcam transições claras entre etapas. Nestes momentos, a coordenação busca consolidar definições entre os envolvidos, evitando retrocede-las posteriormente.

Como parte do processo de reestruturação que a Empresa está buscando, a Coordenadora de Projetos fará mais visitas à obra. Hoje ocorre uma única visita, que atende ao protocolo, mas pouco contribui com melhorias no projeto. Contudo, passará a ser: após a concretagem da primeira laje tipo, após a execução da alvenaria no tipo, na inauguração do apartamento decorado e antes da entrega da obra. Esta medida tende a favorecer o processo de retroalimentação, favorecendo o resultado final.

A partir da análise de modelos propostos por autores nacionais, Fontenelle (2002) destaca a necessidade de estabelecer um "fluxo-base" para o gerenciamento do projeto. A definição de um cronograma para o empreendimento, envolvendo todos os agentes e relacionando seus produtos, é imprescindível para o controle deste processo e sua fluidez.

O cronograma inicial de projeto é elaborado, ao início do anteprojeto, com grande margem de erro, pois há pouco controle sobre o cumprimento dos prazos na fase de projeto. O fluxo de ajustes dos projetos muitas vezes não ocorre dentro do prazo para início da obra, o que requer liberações parciais. Segundo Laufer, Denker e Shenhar (1996), nestes casos, é papel do coordenador isolar as incertezas, evitando retrabalho na obra.

\subsubsection{Desempenho e inovação}

A incorporação de novas soluções normalmente ocorre por demanda do marketing. Não há um trabalho de pesquisa e desenvolvimento interno. As práticas são bastante consolidadas e não se estimula a implantação de novas tecnologias.

Ozorhon (2013) defende que mesmo considerando os custos com pesquisa e desenvolvimento, o investimento em inovação costuma mostrar-se vantajoso, agregando qualidade a desempenho do edifício e gerando economia em situações futuras, onde se possa aplicar a solução desenvolvida. 
Quanto à revisão da Norma de desempenho, em vigor a partir de 2013, a Empresa ainda não definiu sua conduta. Hoje, trabalha com fornecedores reconhecidos e não tem a cultura de fazer ensaios. Na medida do possível, essa relação será mantida no processo de adaptação às normas, com maior exigência de informações técnicas destes parceiros.

\section{CONSIDERAÇÕES FINAIS: MELHORIAS NA GESTÃO DO PROJETO}

\subsection{Motivações para mudança}

Segundo Porter (1989) apud Fabricio (2002), uma das diretrizes que uma empresa pode seguir para prosperar é o foco em um serviço voltado para um determinado nicho de mercado.

Este é o caso da Empresa estudada, que atua em uma área definida da cidade, e oferecendo produtos semelhantes. Ou seja, fixando as principais variáveis do empreendimento, que de acordo com o conceito de CTE apud Fontenelle (2002) são: público-alvo; mercado imobiliário na região; indicadores internos da empresa.

Isto aliado à constância na formação de equipes facilita o gerenciamento do projeto. Contudo, algumas projeções futuras demandam uma mudança nos processos. A primeira é um aumento do número de projetos. Este crescimento requer uma estrutura com procedimentos formalizados que possam garantir a difusão das práticas consolidadas. Isso é necessário, também, para orientar a tomada de decisão, no caso de novos membros na equipe. A segunda questão é a possibilidade de expandir em novos nichos de mercado, respondendo a uma crescente competitividade ou saturação do recorte atual. Neste caso, estabelecer parâmetros, tanto de projeto como construtivos, será uma tarefa complexa e ao mesmo tempo primordial.

Ainda deve-se considerar uma alteração progressiva no perfil do consumidor, mais exigente com relação ao desempenho e a inovação da edificação. Oliveira (2005) destaca que a atenção aos desejos do cliente não é mais um diferencial e que sua não observância pode comprometer a comercialização do produto.

\subsection{Alterações possíveis para a empresa estudada}

Pelo ganho de complexidade nos projetos e na indústria da construção é necessário se aprimorar os mecanismos de gestão do projeto (BIBBY, AUSTIN e BOUCHLAGHEM, 2003). Visto que esta etapa tem grande impacto no custo e na qualidade final da construção, é necessária uma maior atenção a: comunicação, documentação, alocação de recursos, coordenação entre as disciplinas e definição de critérios na tomada de decisões.

O processo de projeto na Empresa apresenta boa coesão interna no formato que assume hoje, principalmente, devido às delimitações de produto e de equipe. Mas a coordenação de projetos, embora atuante, não usa métodos sistemáticos para garantir a qualidade do processo. $\mathrm{O}$ estabelecimento de diretrizes para a elaboração do cronograma e seu uso efetivo como mecanismo de gestão ajudará na equalização dos processos e no maior controle sobre seu andamento. A formalização da comunicação entre agentes também deve ser aprimorada.

O início do processo deve ser marcado pela definição formal das responsabilidades e das diretrizes de projeto. Para tal, os contratos devem seguir um padrão com definição clara de escopo. Do mesmo modo, o Manual de Projeto e o Caderno de Detalhes devem ser mantidos atualizados e completos a fim de direcionar as práticas na empresa. 
Outro aspecto a ser melhorado é a retroalimentação do processo. Os departamentos de obra e projeto encontram-se próximos na estrutura da empresa; o que deve ser visto como um facilitador desta conduta.

É importante, ainda, estruturar o departamento para viabilizar inovações. É necessário dedicação à análise de novas soluções e alternativas às práticas consolidadas. Junto a este esforço, será somado um trabalho de reavaliação dos produtos especificados a fim de atender à nova norma de desempenho NBR 15.575/13; questão para a qual a empresa ainda não estabeleceu um plano de ação.

\section{REFERÊNCIAS}

BIBBY, L.; AUSTIN, S. A.; BOUCHLAGHEM, N. M. Defining an improvement plan to address design management practices within a UK construction company. IT in Architecture, International Journal Engineering and Construction, 2003. 57-66.

CHUA, D. K. H. et al. Process-Parameter-Interface Model for Design Management. Journal of construction engeneering and management, 2003.

FABRICIO, M. M. Projeto simultâneo na construção de edifícios. Tese de doutorado EPUSP. São Paulo. 2002.

FONTENELLE, E. C. Estudos de caso sobre a gestão do projeto em empresas de incorporação e construção. Dissertação de Mestrado - EPUSP. São Paulo. 2002.

KPAMMA, E. Z.; ADJEI-KUMI, T. Management of Waste in the Building Design Process: The Ghanaian Consultants' Perspective. Architectural Engineering and Design Management, 2011.

LAUFER, A.; DENKER, G. R.; SHENHAR, A. J. Simultaneous management: the key to excellence in capital projects. International Journal of Project Management, 1996. 189-199.

MELHADO, S. B.; AGOPYAN, V. O. Conceito de Projeto Na Construção de Edifícios: Diretrizes Para Sua Elaboração e Controle. EPUSP. São Paulo. 1995. (BT/PCC/139).

NÓBREGA JUNIOR, C. L.; MELHADO, S. B. Coordenador de projetos de edificações: estudo e proposta para perfil, atividades e autonomia. EPUSP. São Paulo, p. 227. 2013. (BT/PCC/579).

OLIVEIRA, O. J. D. Modelo de gestão para pequenas empresas de projeto de edifícios. Dissertação de Mestrado - EPUSP. São Paulo. 2005.

OZORHON, B. Analysis of Construction Innovation Process at Project Level. JOURNAL OF MANAGEMENT IN ENGINEERING, 2013.

SILVA, M. V. M. F. P. D. N. C. C. A coordenação de projetos de edificações: estudos de caso. Gestão e Tecnologia de Projetos, 2008.

TRIBELSKY, E. I.; SACKS, R. An Empirical Study of Information Flows in Multidisciplinary Civil Engineering Design Teams using Lean Measures. Architectural Engineering and Design, 2011. 85-101.

TZORTZOPOULOS, P. Contribuições para o desenvolvimento de um modelo do processo de projeto de edificações em empresas construtoras incorporadoras de pequeno porte. Dissertação de Mestrado em Engenharia Civil - UFRS. Porto Alegre. 1999. 